\title{
In-vitro Comparative Study of the use of $2 \%$ Chlorhexidine on Microtensile Bond Strength of Different Dentin Adhesives: A 6 Months Evaluation
}

\author{
Estudio Comparativo in vitro del uso de Clorhexidina al $2 \%$ Sobre la Resistencia de \\ Unión Microtensil de Diferentes Adhesivos Dentinarios: Una Evaluación de 6 Meses
}

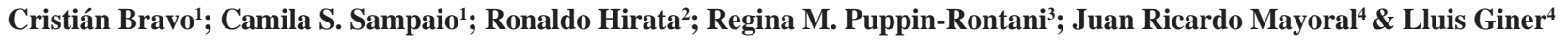

BRAVO, C.; SAMPAIO, C. S.; HIRATA, R.; PUPPIN-RONTANI, R. M.; MAYORAL, J. R. \& GINER, L. In-vitro comparative study of the use of $2 \%$ chlorhexidine on microtensile bond strength of different dentin adhesives: A 6 months evaluation. Int. J. Morphol., 35(3):893-900, 2017.

SUMMARY: The aim of this study was to evaluate the effect of chlorhexidine (CHX) dentin treatment on microtensile bond strength $(\mu \mathrm{TBS})$ of adhesive systems in different storage times. Occlusal enamel was removed from ninety third-molars and flat surfaces of middle dentin were exposed. Teeth were randomly divided in 6 groups according to adhesive system (etch-and-rinse : Adper Scotchbond 1XT - ASB ; self-etch: Adper Prompt L-Pop - APP; and universal: Single Bond Universal - SBU) and chlorhexidine (CHX) dentin treatment ( $2 \%$ CHX application for $20 \mathrm{~s}$ prior Primer). After resin composite build up, teeth were sectioned to obtain beam specimens and divided in 3 subgroups ( $\mathrm{n}=5)$ : $72 \mathrm{~h}, 3$ and 6 months storage times. After the storage times, teeth were tested in tension until failure ( 0.5 $\mathrm{mm} / \mathrm{min}$ ). SEM was performed to observe hybrid layer of adhesive systems. Data were analyzed using one-way ANOVA and Tukey tests. At $72 \mathrm{~h}$, all equivalent groups (same adhesive system, different dentin treatments) maintained their $\mu$ TBS when compared CHXtreatment. At 3 and 6 months, non-treated CHX groups showed less $\mu$ TBS than CHX-treated ones. Six months storage time did not significantly decrease $\mu$ TBS, except for G2-ASB. The effect of CHX on dentin $\mu$ TBS depends on storage times and adhesive systems. While immediate $\mu$ TBS was not affected by CHX treatment, CHX improved dentin $\mu$ TBS after 3 and 6 months.

KEY WORDS: Microtensile bond strength, Dentin, Chlorhexidine, Dentin adhesives, Adhesion

\section{INTRODUCTION}

Adhesive interface is one of the most concerning factors related to long-term resin composite restorations. Clinically, bonding failure is frequently associated with retention loss of adhesive restorations, marginal defects, lack of marginal adaptation and marginal discoloration, which can decrease the restoration durability (Hickel \& Manhart, 2001; Peumans et al., 2005; Heintze et al., 2010).

Although immediate bonding is usually successful, after certain time, the longevity of the adhesive interface remains questionable due to challenging physical and chemical factors, such as occlusal forces, expansion and contraction stresses related to temperature changes, among others (Breschi et al., 2008).
Matrix Metalloproteinases (MMPs) belong to a group of zinc- and calcium- dependent enzymes that cleave native collagenous tissues. It is well known that dentin matrix contains such MMPs, and that once they are activated by odds such as adhesive procedures, they can slowly degrade the collagen fibrils of resin-infiltrated hybrid layers (De Munck et al., 2010; Pashley et al., 2011). So, in order to increase the long term of restorative procedures, multiple studies have focused on methods to preserve dentine bonding (André et al.; Breschi et al., 2008; Nishitani et al., 2013; Stanislawczuk et al., 2014; Hirata et al., 2016; Tekçe et al., 2016). One of the most commonly used MMPs enzyme inhibitor is chlorhexidine (CHX), since it prevents the destruction of the adhesive interface over time (Tekçe et al.).

${ }^{1}$ College of Dentistry, Universidad de los Andes, Santiago, Chile.

${ }^{2}$ New York University College of Dentistry, New York, USA.

${ }^{3}$ University of Campinas - Piracicaba Dental School, Piracicaba, SP, Brazil.

${ }^{4}$ College of Dentistry, Universitat Internacional de Catalunya, Barcelona, Spain. 
BRAVO, C.; SAMPAIO, C. S.; HIRATA, R.; PUPPIN-RONTANI, R. M.; MAYORAL, J. R. \& GINER, L. In-vitro comparative study of the use of $2 \%$ chlorhexidine on microtensile bond strength of different dentin adhesives: A 6 months evaluation. Int. J. Morphol., 35(3):893-900, 2017.

A recent study showed MMP activation due to adhesive application (Breschi et al., 2010), which is a matter of concern when dealing with adhesive restorations. This same research also showed an adhesive-activated enzyme inhibition with CHX application. It is thought that CHX can inhibit the MMP activity in the hybrid layer, increasing the long-term durability of resin-dentin bonds (Breschi et al., 2010). Addition of CHX to adhesives was capable of preventing and minimizing the degradation of resin-dentin bonds over a 1-year period (Stanislawczuk et al.). The absence of nanoleakage in CHX-treated specimens also demonstrates a well-preserved hybrid layer due to its inhibiting effect on dentin MMP-2 activity (Breschi et al., 2010).

Several approaches have been proposed for adhesive bonded restorations, and different types of adhesive systems might promote also different patterns of bond strength. Results in loss of adhesion of resin composites to dentin can be measured as a significant decrease in the microtensile bond strength ( $\mu$ TBS) (Armstrong et al., 2010). The etch-and-rinse approach relies on acid etching of both enamel and dentin to increase the permeability of resins in those substrates (Pashley et al.). Application of $37 \mathrm{wt} . \%$ phosphoric acid demineralizes $5-8 \mathrm{~mm}$ of the intertubular dentin matrix surface, creating nanometer-sized porosities within the underlying collagen fibrillar matrix (Pashley et al.). This allows infiltration of solvated comonomers into and around collagen fibrils to gain retention for tooth colored resin-composite fillings (Vaidyanathan et al., 2009). On the other hand, the selfetching approach is based on the absence of a separate etching step, as they contain acidic monomers that simultaneously 'condition' and 'prime' the dental substrate. Consequently, this approach has been claimed to be user-friendlier (shorter application time, less steps) and less technique-sensitive (no wet-bonding, simple drying) (Van Meerbeek et al., 2011). Lastly, Universal adhesives represent the newest generation of adhesives on the market. Although they are designed under the "allin-one" concept of the one-step self-etch adhesives, it is possible to also use them in the etch-and-rinse mode (Tekçe et al.).

Thus, the aim of this study was to evaluate the effect of chlorhexidine dentin treatment on the microtensile dentin bond strength of different adhesive systems (etchand-rinse, self-etch and universal) at different storage times ( 72 hours, 3 months and 6 months). The hypothesis tested were that (1) CHX treatment would result in higher bond strengths compared to groups without $\mathrm{CHX}$ treatment; and (2) increased storage times would present higher degradations in microtensile bond strengths.

\section{MATERIAL AND METHOD}

Samples Preparation. Ninety sound and freshly extracted human third molars were obtained according to protocols approved by Universidad de Los Andes, Chile, Institutional Review Board. Teeth were cleaned and kept in distilled water at room temperature until their use.

The following adhesive systems were used: one etchand-rinse (ASB, Adper Scotchbond 1XT, 3M ESPE, St. Paul, MN, USA), one self-etch (APP, Adper Prompt L-Pop, 3M ESPE, St. Paul, MN, USA) and one universal (SBU, Single Bond Universal, 3M ESPE, St. Paul, MN, USA) in the selfetch mode, each of them being used with and without dentin treatment with a cavity disinfectant before primer/adhesive application (CHX, 2 \% Chlorhexidine, Cavity Cleanser, Bisco, Inc., Schaumburg, IL, USA), applied for $20 \mathrm{~s}$.

After cleaning, teeth were randomly divided in six groups $(\mathrm{n}=15$ each): G1-ASB+CHX; G2-ASB; G3APP+CHX; G4-APP; G5-SBU+CHX; G6-SBU. All groups were restored with the same resin composite (Filtek Z350 XT, 3M ESPE, St. Paul, MN, USA).

Application protocol for each group was performed as follows: G1 (ASB+CHX) - dentin etch for 15s (37\% ScotchBond Etchant, 3M ESPE, St. Paul, MN, USA), water rinse for $30 \mathrm{~s}$ and gently dried with a cotton pellet. Application of CHX with a microbrush for $20 \mathrm{~s}$ and lightly air-dry for $10 \mathrm{~s}$. Application of the single-component adhesive Adper Scotchbond 1XT followed by lightpolymerization (Bluephase G2, Ivoclar Vivadent) according to manufacturer's instructions. Resin composite incrementally build-up until $5 \mathrm{~mm}$ height ( 5 increments, $1 \mathrm{~mm}$ each) with Filtek Z350 XT (3M ESPE), each layer being light-polymerized for $20 \mathrm{~s}$ (Bluephase G2, Ivoclat Vivadent); G2(ASB) - G2 followed the same steps previously described for $\mathrm{G} 1$, except for the application of $\mathrm{CHX}$; G3(APP+CHX) - Application of CHX as previously described, application of the self-etch adhesive system Adper Prompt L-Pop followed by light-polymerization according to manufacturer's instructions. Resin composite build-up was performed following the same steps previously described for G1. G4(APP) - G4 followed the same steps previously described for $\mathrm{G} 3$, except for the application of $\mathrm{CHX}$; G5(SBU+CHX) - Application of CHX followed by application of the universal adhesive system and lightpolymerization according to the self-etch protocol of the manufacturer's instructions. Resin composite build-up performed following the same steps previously described for G1. G6(SBU) - G6 followed the same steps previously described for G5, except for the application of CHX. 
Microtensile Bond Strength Test ( $\mu$ TBS). Teeth were mounted in acrylic resin in order to facilitate sample preparation. Occlusal enamel of each tooth was removed perpendicular to the long axis and flat surfaces of middle dentin were exposed with a slow speed diamond saw (IsoMet 1000, Buehler, Lake Bluff, IL, USA). Cut surfaces were polished with 620-grit SIC paper discs (Buehler) in order to standardize the smear layer for the bonding procedures.

After the restoration procedures, teeth were stored in water for $24 \mathrm{~h}$ before cutting procedures. Afterwards, restored teeth were serially sectioned longitudinally to the bonded interface with a low-speed diamond saw in a precision cutting machine (IsoMet 1000, Buehler) under water cooling to obtain bonded beams specimens with a cross-sectional area of approximately $1 \mathrm{~mm}^{2}$, with approximately $5 \mathrm{~mm}$ of resin composite material and $5 \mathrm{~mm}$ of dentin tissue. The exact dimension of each beam was measured using a digital caliper and 4 sticks were evaluated per tooth. Teeth were subdivided into 3 subgroups, according to the storage time ( $n=5$ each): $72 \mathrm{~h}, 3$ months and 6 months (distilled water at room temperature).

After the designated storage period, each beam was fixed to a microtensile device with a cyanoacrylate-based adhesive (Zapit, Dental Ventures of America, Corona, CA, USA) and attached to a universal testing machine (Z100, Zwick Roell, Germany). Specimens were tested with a head speed of $0.5 \mathrm{~mm} / \mathrm{min}$ and loaded until failure. The crosssectional area of each specimen was divided by the peak tensile load at failure to calculate the bond strength in MPa.

Stereoscopic Microscopy and Scanning Electronic Microscopy. After completing the test, each beam was evaluated with a stereoscopic microscope in order to identify the types of failures: adhesive (failure between tooth and restoration material); cohesive in composite (failure within the restoration material); cohesive in dentin (failure within dentin); or mixed (both cohesive and adhesive). Scanning electronic microscopy was used to analyze the hybrid layers among the different adhesive systems.
Statistical Analysis. One-way ANOVA and Post-hoc tests were conducted to compare the groups with and without CHX treatment of each separate adhesive protocol, at each storage time.

\section{RESULTS}

Mean average of dentin bond strength of adhesive systems for the three evaluation storage times, according to CHX treatment, are showed in Table I. Results data revealed a statistical difference between groups regarding storage times, for 72 hours, 3 months and 6 months ( $\mathrm{p} \leq 0.05$ ). Also, statistical difference was observed when compared CHX treatment $(\mathrm{p} \leq 0.05)$, and adhesive systems $(\mathrm{p} \leq 0.05)$.

The CHX dentin treatment resulted in either significant increased $(p \leq 0.05)$ bond strength or maintenance $(p \geq 0.05)$ of the bond strength compared to the same equivalent group without the CHX dentin treatment, depending on the storage times. At 72 hours, none of the compared equivalent groups (same adhesive system, CHX-treated versus non-treated) presented significant difference in bond strengths $(\mathrm{p} \geq 0.05)$. However, when different adhesive systems were compared at the same dentin treatment, Group 4 (APP) presented significantly lower bond strength compared to G2 - ASB $(\mathrm{p}=0.010)$ and $\mathrm{G6}-\mathrm{SBU}(\mathrm{p}=0.004)$.

When evaluated 3 months storage time, a significant decrease $(\mathrm{p} \leq 0.05)$ was observed for all non-treated groups when compared to the respective CHX-treated groups. All groups presented higher bond strengths when CHX was applied $(\mathrm{p} \leq 0.05)$. Moreover, when comparing adhesive systems within the same dentin treatment, G5 - SBU+CHX showed the highest bond strength, significantly different than $\mathrm{G} 1-\mathrm{ASB}+\mathrm{CHX}(\mathrm{p}=0.007)$ and $\mathrm{G} 3-\mathrm{APP}+\mathrm{CHX}(\mathrm{p}=0.000)$, which were not significant different within each other $(\mathrm{p} \geq 0.05)$. Comparing the non-CHX treated groups, G2 (ASB) and G4 (APP) presented the lowest bond strengths, although not significantly different than G6 (SBU) ( $\mathrm{p} \geq 0.05)$.

Table I. Bond strength means (standard deviation) from different groups concerning different storage times.

\begin{tabular}{llll}
\hline & 72 hours & 3 months & 6 months \\
\hline G1 - ASB + CHX & $26.28(9.29) \mathrm{ABa}$ & $32.26(10.33) \mathrm{Ba}$ & $31.73(5.18) \mathrm{ABa}$ \\
$\mathrm{G} 2-\mathrm{ASB}$ & $28.56(5.83) \mathrm{Aa}$ & $19.82(7.65) \mathrm{Cb}$ & $23.39(5.69) \mathrm{CDb}$ \\
$\mathrm{G} 3-\mathrm{APP}+\mathrm{CHX}$ & $24.21(7.52) \mathrm{ABa}$ & $28.51(13.18) \mathrm{BCa}$ & $27.37(4.40) \mathrm{BCa}$ \\
$\mathrm{G} 4-\mathrm{APP}$ & $20.14(4.87) \mathrm{Ba}$ & $20.86(6.13) \mathrm{Ca}$ & $20.51(5.66) \mathrm{Da}$ \\
$\mathrm{G} 5-\mathrm{SBU}+\mathrm{CHX}$ & $28.43(9.78) \mathrm{Ab}$ & $44.11(12.09) \mathrm{Aa}$ & $36.88(6.65) \mathrm{Aa}$ \\
$\mathrm{G} 6-\mathrm{SBU}$ & $29.24(7.90) \mathrm{Aa}$ & $23.54(12.09) \mathrm{BCa}$ & $23.62(7.07) \mathrm{CDa}$ \\
\hline
\end{tabular}

Means followed by different letters (upper cases in columns and lower cases in rows) were statistically different ( $\mathrm{p} \leq 0.05)$. 
After 6 months storage time, the same pattern as of the 3 months' time was observed. For all groups, the treatment with CHX promoted higher bond strength values $(\mathrm{p} \leq 0.05)$. Again, G5 (SBU+CHX) presented higher bond strength, although not significantly different $(\mathrm{p}=0.067)$ than G1 (ASB+CHX). Group 3 (APP+CHX) also did not show a statistical difference $(p=0.179)$ compared to $G 1$ (ASB+CHX). On the other hand, when no CHX was applied, the self-etching group (G4 - APP) showed the lowest values of bond strength, although not significantly different than G2 (ASB - $\mathrm{p}=0.628)$ and G6 (SBU - $\mathrm{p}=0.546)$.

Concerning the same groups in different storage times, most of the groups maintained their bond strengths (p. $\geq 0.05$ ), except for G2 (ASB), where a significant decrease in bond strength was observed after $3(\mathrm{p}=0.000)$ and 6 months
( $\mathrm{p}=0.037$ ) storage times compared to the baseline; and for G5 (SBU+CHX), where a different pattern was observed and bond strength results from 3 and 6 months were significantly higher compared to $72 \mathrm{~h}(\mathrm{p} \leq 0.05)$.

When evaluating failure patterns, whatever the storage time or $\mathrm{CHX}$ application evaluated, mixed failures were the most observed within groups, ranging from 70-80 $\%$. Adhesive failure was the second most observed, ranging from $15-25 \%$. Cohesive failure in dentin ranged from 5-20 $\%$, and cohesive failure in composite was only observed in one group (Fig. 1). Scanning electronic microscopy images depicted longer resin tags for the etch-and-rinse adhesive system (ASB), followed by the 'strong' self-etch adhesive system (APP), and only a smear layer interaction for the universal adhesive (SBU) (Fig. 2).

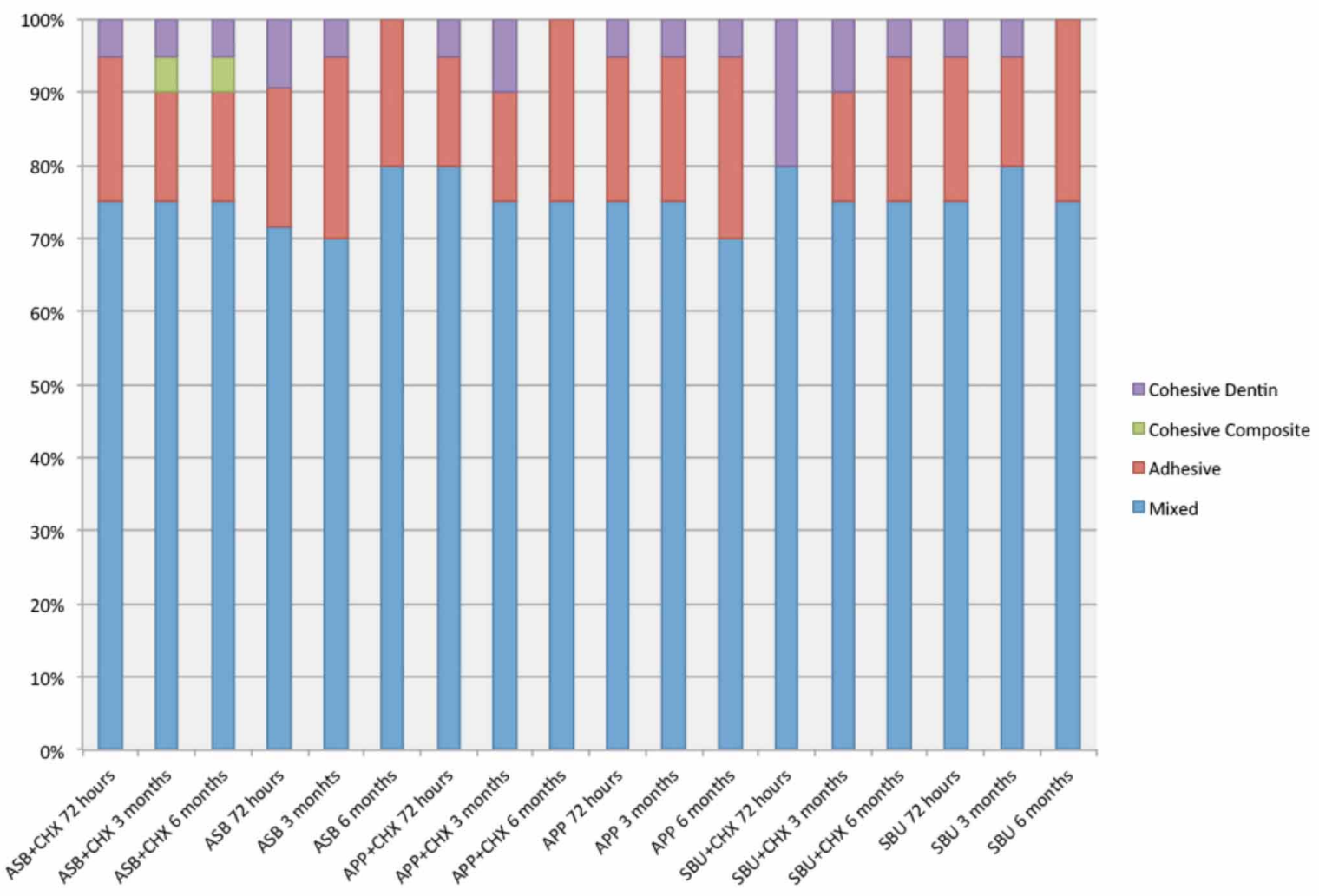

Fig. 1. Distribution of failure modes regarding storage times, adhesive systems and CHX treatment.

\section{DISCUSSION}

Enzymatic collagen matrix degradation by hostderived enzymes such as MMPs plays a significant role in the destruction of bonded interfaces (Tjäderhane et al., 2013). Studies have found that these enzymes can be activated by the simple adhesive system application on dentin substrate, leaving it exposed to collagenolytic activity and start a degradation of the dentin-bonded interface (Breschi et al., 2010; De Munck et al., 2010), resulting in loss of adhesion of resin composites to this substrate, which can be measured as a decrease in bond strength. However, this fact is still 


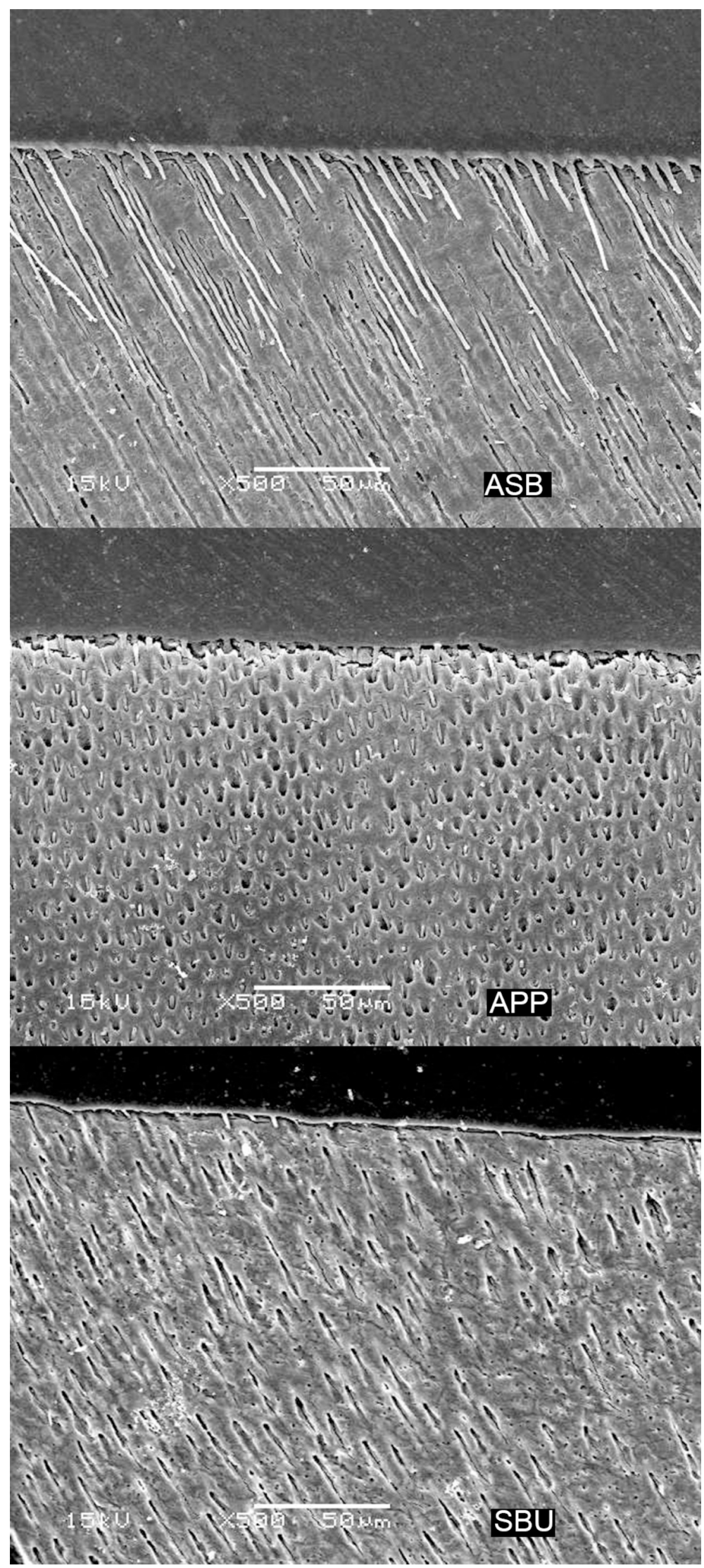

contradictory, since an increased dentin MMP activity has been reported, when phosphoric acid is used (Breschi et al., 2010; De Munck et al., 2009), while other studies reported that phosphoric acid decreased dentin MMP activity under different experimental conditions (Mazzoni et al., 2006). Self-etching adhesives have also been shown to increase (Nishitani et al., 2006; Lehmann et al., 2009) or not affect MMPs activity (De Munck et al., 2009). Thus, in order to surpass this problem and block enzymatic degradation while preserving hybrid layers, the application of CHX to dentin has been investigated (Breschi et al., 2010; Stanislawczuk et al.; Tekçe et al.).

The first research hypothesis, which tested whether CHX dentin treatment would result in higher bond strengths compared to nontreated groups, was accepted. This fact was observed more after 3 and 6 months of storage times, while $72 \mathrm{~h}$ bond strength was not affected when analyzing the same equivalent groups (same adhesives compared with or without CHX treatment). However, at this period of time, the one-step self-etching adhesive system (APP) presented lower bond strengths when no CHX was applied (G4 - APP) compared to both G2 ASB and G6 - SBU. At 3 months, all equivalent groups showed a decrease in bond strength when no CHX was applied, and the Universal adhesive system (SBU) presented the highest bond strength values when CHX was applied. At 6 months, again the same pattern was observed, and all adhesives showed higher bond strengths when CHX was applied.

Fig. 2. SEM micrographs (magnification: x500) of the etch-and-rinse (Adper Scotchbond 1XT - ASB), 'strong' self-etch (Adper Prompt L-Pop - APP) and universal (Single Bond Universal - SBU) adhesive systems used in this study. Hybrid layers were exposed with a slow speed saw and dentin was dissolved by sequential rinses in hydrochloric acid and sodium hypochlorite to reveal resin penetration. It can easily be observed the difference within the resin tags among the different adhesive systems. The etch-and-rinse adhesive (ASB) infiltrated dentin tubules deeper due to the use of the etching agent. The 'strong' self-etching adhesive (APP) still penetrated in the dentin tubules, but less deep than the etch-and-rinse group. Universal adhesive (SBU) infiltrated no further than the smear layer and smear plugs, not showing long resin tags, due to its $\mathrm{pH}$. 
It is well known that adhesion to enamel and dentin play different roles in longevity of resin composite restorations. Due to the complex approach that is bonding to dentin, different methods have been studied in order to improve its adhesion, such as the application of plasma (Hirata et al.), benzalkonium chloride (Tekçe et al.), ethylenediaminetetracetic acid (EDTA) (Tekçe et al.), chlorhexidine (Breschi et al., 2010; Nishitani et al., 2013; Stanislawczuk et al.; Tekçe et al.), among others. Regarding all those methods, CHX is the most studied (Breschi et al., 2010; Nishitani et al., 2013; Stanislawczuk et al.; Tekçe et al.; André et al., 2015), with good performance results when concerning MMP inhibition and longevity of the adhesive interface (Breschi et al., 2010).

Chlorhexidine is an amphipathic molecule that binds to several proteins by a cation-chelating mechanism (Negrelo Newton et al., 2004). By a similar chelating mechanism, chlorhexidine prevents binding of ions such as zinc or calcium to the MMP, and so inhibits its catalytic activity (Negrelo Newton et al.). In our study, the use of CHX showed improved bond strength when compared to groups without the dentin treatment with this cavity disinfectant. Others authors had shown an increase in the bond durability of adhesive systems (Breschi et al., 2010; Tekçe et al.), as well as a bactericidal effect after 5 minutes of direct contact 1 and a lower interfacial nanoleakage expression (Breschi et al., 2010) when CHX treatment of dentin was performed.

The second research hypothesis, that tested whether the increased storage times would present higher degradations in the microtensile bond strengths or not, was partially accepted. In our study, for most of the adhesive systems, the $\mu$ TBS kept consistent even after 6 months of storage time. This is in accordance to other studies, which showed that most adhesives did not present a significant decrease in $\mu \mathrm{TBS}$ even after 1 year of storage in artificial saliva (André et al.).

Hydrolysis is a chemical process that breaks covalent bonds between the polymers by addition of water to ester bonds, resulting in loss of the resin mass, which is considered as one of the main reasons for resin degradation within the hybrid layer, contributing to the reduction in bond strengths created by dentin adhesives over time (Tay \& Pashley, 2003). In our study, only Group 2 (ASB), non-CHX treated, presented a decrease in bond strength after 3 and 6 months of storage in distilled water.

All groups with CHX application showed no difference at 3 and 6 months evaluation. The effect of addition of CHX to the adhesives was tested before, showing a potential for preventing or minimizing the degradation of the resin-dentine bonds in 1 year storage time (Stanislawczuk et al.). However, a study with a longer storage time was able to discriminate a difference in $\mu$ TBS after 2 years of storage (Breschi et al., 2010). Results from those authors depicted a reduction on $\mu$ TBS significantly higher for specimens without CHX dentin treatment, as well as loss of hybrid layer integrity and increased nanoleakage (Breschi et al., 2010). On the other hand, they also observed that for the specimens treated with CHX, absence of nanoleakage was observed after 2 years of storage (Breschi et al., 2010).

The investigation of failure pattern is an important tool in order to identify the weakest area of the dentinecomposite interface created by adhesives (André et al.). Within the results observed in this study, mixed failures were the most seen independent on the storage times or application of CHX. It demonstrated that bonded interface could have remained stable within the periods of times. This finding can be explained by the relative short storage time $(6$ months), which was not enough to indicate changes in dentincomposite interface over time for most of the adhesives. Possibly, increased storage times would have been able to present different failure patterns, once it was proved a decrease in bond strength after 2 years storage time (Breschi et al., 2010), although it was not seen after 1 year storage (André et al.).

It is known that the type of adhesive system used on restoration procedures may affect their clinical performance and longevity (Heintze et al.). 'Etch-and-rinse' adhesives involve a separate etch-and-rinse phase with phosphoric acid (Pashley et al.), while 'self-etch' adhesives are based on the use of non-rinse acidic monomers that simultaneously condition and prime dentin (Van Meerbeek et al.), and showed by SEM to penetrate deeper into dentin, when compared to self-etch protocols. The most recent universal (multi-mode) dental adhesives consist of co-polymers (such as polyacrylic acid), fillers and silane molecules, and can be used in either etch-and-rinse or self-etch approaches (Tekçe et al.). MMPs can be activated by the simple step of conditioning dentin with phosphoric acid (De Munck et al., 2009). Thus, the use of etch-and-rinse adhesive systems might produce a higher activation of endogenous MMPs in dentin, while in self-etching adhesive systems it is less pronounced (De Munck et al., 2009; Osorio et al., 2011), which can be translated in decreased interface degradation. In our study, this fact was not observed, since the etch-andrinse adhesive system did not show a higher degradation compared to the self-etch adhesive system. This fact can be explained because, in our study, the self-etching adhesive system presents a really low $\mathrm{pH}(=1.0)$. It is known that, although 'mild' self-etching adhesive systems are less prone to activate MMPs, when using 'strong' self-etching adhesive 
systems, their releasing can be promoted (De Munck et al., 2009). Following this idea, regarding the use of the universal adhesive system in a self-etching approach, our results corroborates to previous studies (De Munck et al., 2009). Since the Universal adhesive used in our study presents a $\mathrm{pH}=2.7$, likely it was less capable of activating endogenous MMPs from dentin, which may explain the higher dentin bond strength results obtained after storage times of 3 months and 6 months, compared to the other adhesive systems. The pHs of each adhesive system and acid etching can also explain the SEM micrographs. The etch-and-rinse adhesive system promoted longer resin tags due to the use of the phosphoric acid, while the 'strong' self-etch adhesive system showed shorter resin tags and the universal adhesive system showed just a few resin tags and only a interaction with the smear layer. Acid dentin treatment facilitates the release of the MMPs enzymes, without entering directly into contact with the enzyme and therefore without destroying it (De Munck et al., 2009). Chlorhexidine, even when used in low concentrations, might be able to inhibit such activity and arrest the degradation of the hybrid layers, mostly in etch-and-rinse adhesive systems (Hebling et al., 2005).

Irrespective of the etch-and-rinse or the self-etch strategy, by combining hydrophilic and ionic resin monomers into the bonding agent, such as in simplified adhesives (i.e. two-step etch-and-rinse and one-step selfetch systems), the bonded interface lacks a nonsolvated hydrophobic resin coating (Breschi et al., 2008). Any kind of simplification in the clinical application procedure might result in lower bond strengths, incomplete adhesive films polymerization and increased adhesive permeability (Cadenaro et al., 2005). However, various clinical procedures were proposed to optimize bonding and reduce aging, such as extended polymerization time and use of MMPs inhibitors (Breschi et al., 2008; Cadenaro et al.), as used in this study. Thus, the use of simplified adhesive systems must be chosen with caution, and if possible, accompanied by disinfection protocols such as $\mathrm{CHX}$ or other optimized bonding protocols. Further studies should focus on the long term of simplified adhesive systems.

Under the limitations of this study, it can be concluded that CHX application influences on dentin adhesion in different time storages and adhesive procedures. When CHX dentin treatment was used, higher bond strengths values were seen compared to the same groups without treatment, for 3 and 6 months. The use of CHX treatment for all simplified bonding procedures, being etch-and-rinse, 'strong' self-etch or universal adhesive systems, can improve the bond strength to dentin substrate.

\section{ACKNOWLEDGEMENTS}

The authors thank 3M ESPE for donation of the materials. This work was supported by Universidad de los Andes, Chile.

BRAVO, C.; SAMPAIO, C. S.; HIRATA, R.; PUPPINRONTANI, R. M.; MAYORAL, J. R. \& GINER, L. Estudio comparativo in vitro del uso de clorhexidina al $2 \%$ sobre la resistencia de unión microtensil de diferentes adhesivos dentinarios: Una evaluación de 6 meses. Int. J. Morphol., 35(3):893-900, 2017.

RESUMEN: El objetivo de este estudio fue evaluar el efecto del tratamiento con clorhexidina $(\mathrm{CHX})$ de la dentina sobre la resistencia de la unión microtensil (mTBS) de los sistemas adhesivos en diferentes tiempos de almacenamiento. Se retiró el esmalte oclusal de noventa terceros molares y se expusieron superficies planas de la dentina media. Los dientes se dividieron al azar en 6 grupos de acuerdo con el sistema adhesivo (con grabado ácido: Adper Scotchbond 1XT-ASB, auto-grabado: Adper Prompt L-Pop-APP y universal: Single Bond Universal- SBU) y el tratamiento de la dentina con clorhexidina (CHX) (aplicación de CHX al $2 \% 20 \mathrm{~s}$ antes del Primer). Después de la aplicación de la resina compuesta, los dientes fueron seccionados para obtener muestras en forma de barras y divididos en 3 subgrupos $(n=5)$ con tiempos de almacenamiento de 72 h, 3 y 6 meses. Después de los tiempos de almacenamiento, los dientes se sometieron a tensión hasta la fractura $(0,5 \mathrm{~mm} / \mathrm{min})$. SEM se realizó para observar la capa híbrida de sistemas adhesivos. Los datos se analizaron mediante ANOVA unidireccional y pruebas de Tukey. A las $72 \mathrm{~h}$, todos los grupos equivalentes (el mismo sistema adhesivo, diferentes tratamientos de dentina) mantuvieron su mTBS cuando se comparó el tratamiento CHX. A los 3 y 6 meses, los grupos CHX no tratados mostraron menos mTBS que los tratados con CHX. Seis meses de tiempo de almacenamiento no disminuyó significativamente el mTBS, excepto para el G2-ASB. El efecto de CHX sobre la dentina mTBS depende del tiempo de almacenamiento y de los sistemas adhesivos. Mientras que el mTBS inmediato no se vio afectado por el tratamiento con CHX, CHX mejoró la mTBS a dentina después de 3 y 6 meses.

PALABRAS CLAVE: Resistencia de la unión microtensil; Dentina; Clorhexidina; Adhesivos dentinarios; Adhesión.

\section{REFERENCES}

André, C. B.; Gomes, B. P.; Duque, T. M.; Stipp, R. N.; Chan, D. C.; Ambrosano, G. M. \& Giannini, M. Dentine bond strength and antimicrobial activity evaluation of adhesive systems. J. Dent., 43(4):466-75, 2015.

Armstrong, S.; Geraldeli, S.; Maia, R.; Raposo, L. H.; Soares, C. J. \& Yamagawa, J. Adhesion to tooth structure: a critical review of "micro" bond strength test methods. Dent. Mater, 26(2):e50-62, 2010. 
Breschi, L.; Mazzoni, A.; Nato, F.; Carrilho, M.; Visintini, E.; Tjäderhane, L.; Ruggeri, A. Jr.; Tay, F. R.; Dorigo, E. de S. \& Pashley, D. H. Chlorhexidine stabilizes the adhesive interface: a 2-year in vitro study. Dent. Mater., 26(4):320-5, 2010.

Breschi, L.; Mazzoni, A.; Ruggeri, A.; Cadenaro, M.; Di Lenarda, R. \& De Stefano Dorigo, E. Dental adhesion review: aging and stability of the bonded interface. Dent. Mater., 24(1):90-101, 2008.

Cadenaro, M.; Antoniolli, F.; Sauro, S.; Tay, F. R.; Di Lenarda, R.; Prati, C.; Biasotto, M.; Contardo, L. \& Breschi, L. Degree of conversion and permeability of dental adhesives. Eur. J. Oral Sci., 113(6):525-30, 2005.

De Munck, J.; Mine, A.; Van den Steen, P. E.; Van Landuyt, K. L.; Poitevin, A.; Opdenakker, G. \& Van Meerbeek, B. Enzymatic degradation of adhesive-dentin interfaces produced by mild self-etch adhesives. Eur. J. Oral Sci., 118(5):494-501, 2010.

De Munck, J.; Van den Steen, P. E.; Mine, A.; Van Landuyt, K. L.; Poitevin, A.; Opdenakker, G. \& Van Meerbeek, B. Inhibition of enzymatic degradation of adhesive-dentin interfaces. J. Dent. Res., 88(12):11016, 2009.

Hebling, J.; Pashley, D. H.; Tjäderhane, L. \& Tay, F. R. Chlorhexidine arrests subclinical degradation of dentin hybrid layers in vivo. J. Dent. Res., 84(8):741-6, 2005.

Heintze, S. D.; Ruffieux, C. \& Rousson, V. Clinical performance of cervical restorations--a meta-analysis. Dent. Mater, 26(10):993-1000, 2010.

Hickel, R. \& Manhart, J. Longevity of restorations in posterior teeth and reasons for failure. J. Adhes. Dent., 3(1):45-64, 2001.

Hirata, R.; Sampaio, C.; Machado, L. S.; Coelho, P. G.; Thompson, V. P.; Duarte, S.; Ayres, A. P. \& Giannini, M. Short- and long-term evaluation of dentin-resin interfaces formed by etch-and-rinse adhesives on plasma-treated dentin. J. Adhes. Dent., 18(3):215-22, 2016.

Lehmann, N.; Debret, R.; Roméas, A.; Magloire, H.; Degrange, M.; Bleicher, F.; Sommer, P. \& Seux, D. Self-etching increases matrix metalloproteinase expression in the dentin-pulp complex. J. Dent. Res., 88(1):77-82, 2009.

Mazzoni, A.; Pashley, D. H.; Nishitani, Y.; Breschi, L.; Mannello, F.; Tjäderhane, L.; Toledano, M.; Pashley, E. L. \& Tay, F. R. Reactivation of inactivated endogenous proteolytic activities in phosphoric acidetched dentine by etch-and-rinse adhesives. Biomaterials, 27(25):44706, 2006.

Negrelo Newton, A. P.; Cadena, S. M.; Merlin Rocha, M. E.; Skäre Carnieri, E. G. \& Martinelli de Oliveira, M. B. New data on biological effects of chlorhexidine: $\mathrm{Fe} 2+$ induced lipid peroxidation and mitochondrial permeability transition. Toxicol. Lett., 151(3):407-16, 2004.

Nishitani, Y.; Hosaka, K.; Hoshika, T.; Yoshiyama, M. \& Pashley, D. H. Effects of chlorhexidine in self-etching adhesive: 24 hours results. Dent. Mater., 32(3):420-4, 2013.

Nishitani, Y.; Yoshiyama, M.; Wadgaonkar, B.; Breschi, L.; Mannello, F.; Mazzoni, A.; Carvalho, R. M.; Tjäderhane, L.; Tay, F. R. \& Pashley, D. $\mathrm{H}$. Activation of gelatinolytic/collagenolytic activity in dentin by selfetching adhesives. Eur. J. Oral Sci., 114(2):160-6, 2006.

Osorio, R.; Yamauti, M.; Osorio, E.; Ruiz-Requena, M. E.; Pashley, D.; Tay, F. \& Toledano, M. Effect of dentin etching and chlorhexidine application on metalloproteinase-mediated collagen degradation. Eur. J. Oral Sci., 119(1):79-85, 2011.

Pashley, D. H.; Tay, F. R.; Breschi, L.; Tjäderhane, L.; Carvalho, R. M.; Carrilho, M. \& Tezvergil-Mutluay, A. State of the art etch-and-rinse adhesives. Dent. Mater, 27(1):1-16, 2011.

Peumans, M.; Kanumilli, P.; De Munck, J.; Van Landuyt, K.; Lambrechts, P. \& Van Meerbeek, B. Clinical effectiveness of contemporary adhesives: a systematic review of current clinical trials. Dent. Mater, 21(9):864$81,2005$.

Stanislawczuk, R.; Pereira, F.; Muñoz, M. A.; Luque, I.; Farago, P. V.; Reis, A. \& Loguercio, A. D. Effects of chlorhexidine-containing adhesives on the durability of resin-dentine interfaces. J. Dent., 42(1):39-47, 2014.

Tay, F. R. \& Pashley, D. H. Have dentin adhesives become too hydrophilic? J. Can. Dent. Assoc., 69(11):726-31, 2003.

Tekçe, N.; Tuncer, S.; Demirci, M. \& Balci, S. Do matrix metalloproteinase inhibitors improve the bond durability of universal dental adhesives? Scanning, 38(6):535-44, 2016.

Tjäderhane, L.; Nascimento, F. D.; Breschi, L.; Mazzoni, A.; Tersariol, I. L.; Geraldeli, S.; Tezvergil-Mutluay, A.; Carrilho, M. R.; Carvalho, R. M.; Tay F. R. \& Pashley, D. H. Optimizing dentin bond durability: control of collagen degradation by matrix metalloproteinases and cysteine cathepsins. Dent. Mater., 29(1):116-35, 2013.

Vaidyanathan, M.; Sheehy, E. C.; Gilbert, S. C. \& Beighton, D. Antimicrobial properties of dentine bonding agents determined using in vitro and ex vivo methods. J. Dent., 37(7):514-21, 2009.

Van Meerbeek, B.; Yoshihara, K.; Yoshida, Y.; Mine, A.; De Munck, J. \& Van Landuyt, K. L. State of the art of self-etch adhesives. Dent. Mater. 27(1):17-28, 2011.

\author{
Corresponding author: \\ Cristián Bravo \\ Department of Biomaterials \\ College of Dentistry \\ Universidad de los Andes \\ Av Monseñor Alvaro del Portillo 12,455 \\ Las Condes, Santiago \\ CHILE
}

Email: cbravop@uandes.cl

Received: 31-03-2017

Accepted: 09-05-2017 